\title{
Arborescences
}

Revue d'études françaises

\section{Où est la Seine dans les Tableaux parisiens de Baudelaire ?}

\section{Sébastien Roldan}

Numéro 8, décembre 2018

La Seine littéraire au XIX ${ }^{\mathrm{e}}$ siècle

URI : https://id.erudit.org/iderudit/1055883ar

DOI : https://doi.org/10.7202/1055883ar

Aller au sommaire du numéro

Éditeur(s)

Département d'études françaises, Université de Toronto

ISSN

1925-5357 (numérique)

Découvrir la revue

Citer cet article

Roldan, S. (2018). Où est la Seine dans les Tableaux parisiens de Baudelaire? Arborescences, (8), 46-63. https://doi.org/10.7202/1055883ar

\section{Résumé de l'article}

Où est la Seine dans les Tableaux parisiens ? Cette question toute simple à résoudre en apparence recèle maints pièges qu'il est nécessaire d'examiner si l'on espère offrir un portrait juste et éclairé de l'image du fleuve parisien dans la plus référentielle (et la plus commentée) des sections des Fleurs du Mal. Parmi ces pièges, citons : les liens entre réel et idéal chez Baudelaire, les stratifications vertigineuses du sens dans la poésie baudelairienne, les faux-semblants et les effets spéculaires souvent trompeurs, l'exotisme, le romantisme, le symbolisme... de même que l'abondance de la critique ancienne et récente sur toutes ces questions. La présente étude aborde ces problèmes au fil d'une enquête qui aboutit à un paradoxe tout baudelairien : plus la présence de la Seine se fait ténue au sein de ces Tableaux parisiens, plus elle est significative.
Tous droits réservés @ Département d'études françaises, Université de Toronto, 2019 document est protégé par la loi sur le droit d'auteur. L’utilisation des services d'Érudit (y compris la reproduction) est assujettie à sa politique d'utilisation que vous pouvez consulter en ligne. 


\section{SOMMAIRE}

1 Nicolas Gauthier, Université de Waterloo

Sébastien Roldan, chercheur indépendant

Introduction

6 Janine Gallant, Université de Moncton

La Seine de Mérimée et ses ressorts dramatiques

17 Silvia Baroni, Université de Bologne

Au seuil de l'enfer: la Seine dans La Comédie humaine

33 Nicolas Gauthier, Université de Waterloo

La Seine du crime et les petits métiers parisiens

46 Sébastien Roldan, chercheur indépendant

Où est la Seine dans les Tableaux parisiens de Baudelaire?

64 Valérie Narayana, Université Mount Allison

Géocritique du fleuve dans les mémoires de la Commune de Louise Michel

80 Peter Vantine, Saint Michael's College

Au bord de la Seine avec les Goncourt

102 Lola Kheyar Stibler, Université Sorbonne Nouvelle

«Hydrargyre» de Maurice de Fleury ou l'imagination de la matière 


\title{
Où est la Seine dans les Tableaux parisiens de Baudelaire?
}

\author{
Sébastien Roldan, chercheur indépendant
}

\section{Résumé}

Où est la Seine dans les Tableaux parisiens? Cette question toute simple à résoudre en apparence recèle maints pièges qu'il est nécessaire d'examiner si l'on espère offrir un portrait juste et éclairé de l'image du fleuve parisien dans la plus référentielle (et la plus commentée) des sections des Fleurs du Mal. Parmi ces pièges, citons: les liens entre réel et idéal chez Baudelaire, les stratifications vertigineuses du sens dans la poésie baudelairienne, les fauxsemblants et les effets spéculaires souvent trompeurs, l'exotisme, le romantisme, le symbolisme... de même que l'abondance de la critique ancienne et récente sur toutes ces questions. La présente étude aborde ces problèmes au fil d'une enquête qui aboutit à un paradoxe tout baudelairien: plus la présence de la Seine se fait ténue au sein de ces Tableaux parisiens, plus elle est significative.

C'est, du reste, le caractère de la vraie poésie d'avoir le flot régulier, comme les grands fleuves qui s'approchent de la mer, leur mort et leur infini [...].

(Baudelaire, Théophile Gautier: 126)

Avec un tel titre, la présente réflexion énonce d'emblée un programme réclamant, semble-t-il, une mise en garde. Chercher "où" se trouve la Seine dans les Tableaux parisiens est une entreprise qui, comme toute enquête impliquant Paris ou un aspect particulier de la ville chez Baudelaire, conduit invariablement à interroger le rapport qu'entretient le poète avec la réalité matérielle qui l'entoure, qu'il habite. Par conséquent, s'engager dans cette voie revient à descendre un fleuve en se laissant porter par le courant: peu importe le point de départ, on sait où l'on aboutira.

Reste que le séjour sur l'eau peut être instructif et agréable. Aussi mon ambition de retracer dans ces quelques pages la présence de la Seine jusque dans ses méandres les plus secrets ne poursuit pas l'objectif de redécouvrir ce que la critique baudelairienne récente ou ancienne a cent fois observé (notamment Stierle 1980; Laforgue 1995; Acquisto 2008-2009) et qu'on trouve déjà inscrit en toutes lettres dans la plupart des ouvres de Baudelaire qui nous sont les plus chères, à commencer par La Fanfarlo, nouvelle de 1847: que la nature intéresse médiocrement le poète à moins d'être acculturée de quelque manière, c'est-à-dire poétisée par l'homme; que le réel n'est pour lui qu'une rampe de lancement vers l'idéal et le mythe, ou vers une meilleure compréhension de sa propre subjectivité moderne. Il s'agira plutôt de montrer que chez Baudelaire, au contraire de ses contemporains - qu'on pense à d'influents prédécesseurs (Théophile Gautier) ou à d'illustres successeurs (Paul Verlaine) -, la Seine n'est pas là où on l'attend. Au fil de l'enquête il deviendra clair que, plus la présence du fleuve est discrète au sein des Tableaux parisiens, plus elle est significative, car lourde de sous-entendus qui demandent à être interprétés. Disons-le autrement: plus la Seine brille par son absence, dans ces poèmes, plus elle brille de mille feux.

La deuxième section des Fleurs du Mal, deuxième dans l'ordre de lecture du recueil et deuxième en importance, si l'on considère le nombre de pièces, n'a été créée que pour la deuxième édition, celle 
de 1861. Elle compte dix-huit poèmes, tous relativement courts; plusieurs sont des sonnets, les plus longs font une soixantaine de vers ${ }^{1}$; la plupart ont été rédigés et publiés par Baudelaire de manière concomitante ou postérieure à la première édition de son livre en 1857 , soit sur un intervalle de quatre $\mathrm{ans}^{2}$. Cependant, ce qui procure à ces poèmes leur homogénéité, c'est leur aptitude commune à croquer le Paris de l'époque, à rendre fidèlement compte de situations ou de dynamiques typiquement parisiennes. S'il faut en croire le titre sous lequel l'auteur les a rassemblés, chacun cadre un coin de la ville pour le donner à voir dans la fixité mouvante qui définit le genre du "tableau ${ }^{3}$ ». À tout le moins peut-on s'attendre, en feuilletant ces quelque vingt-cinq pages du livre, à trouver des vues ayant pour arrière-plan la ville de Paris ou comportant quelque détail caractéristiquement parisien. C'est le cas: le regard posé par le poète croise le Louvre, le quartier du Carrousel, les théâtres, les cafés, les bouges nocturnes, les foules, l'émeute, etc.

Le fleuve emblématique qui coupe Paris en deux n'est pas en reste, certes, puisqu'il est mentionné par deux fois, d'abord dans le douzième poème, "Danse macabre», puis à la dernière strophe du dixhuitième et dernier, "Le crépuscule du matin». Autrement dit, aux deux tiers et à la toute fin ${ }^{4}$. La première apparition nominative de la Seine souligne "Le branle universel de la danse macabre» qui entraîne tout un chacun: "Des quais froids de la Seine aux bords brûlants du Gange,/Le troupeau

1. Seul le poème «Les Petites Vieilles», divisé en quatre parties d'inégale longueur, dépasse cette marque avec ses quatrevingt-quatre alexandrins.

2. Huit des dix-huit poèmes sont repris de la section Spleen et idéal de la première édition, notamment "Le soleil», "Je n'ai pas oublié, voisine de la ville», «Brumes et pluies», les deux "Crépuscules». Les dix autres parurent en préoriginale entre 1857 et 1861 dans des revues comme Le Présent ("Paysage»), L'Artiste ("À une passante»), La Causerie ( LLe cygne») ou la Revue contemporaine («Les sept vieillards», «Danse macabre», «Rêve parisien»); soulignons que les pièces qui retiendront davantage notre attention appartiennent toutes à ce deuxième groupe.

3. Il convient de préciser dès à présent le réseau de significations véhiculées par ce mot en 1861. Rappelons d'abord la pratique du "tableau vivant», rattachée à l'interprétation dramatique: "Représentation vive et naturelle d'une chose, soit en action, soit de vive voix, soit par écrit» (Littré 1874: t. IV, 2124). Baudelaire critique d'art utilise la locution «tableaux vivants» en 1863 pour parler de choses vues qui sont «de grandes fêtes pour les yeux" et qui en cela constituent d'authentiques aubaines pour l'artiste en quête de sujets à représenter, étant "surprenants, décalqués sur la vie elle-même, éléments d'un pittoresque précieux que beaucoup de peintres en renom, placés dans les mêmes circonstances, auraient étourdiment négligés» (Le Peintre de la vie moderne: 700-701). Une nuance additionnelle est apportée par le Grand Dictionnaire universel du XIX siècle de Pierre Larousse, pour qui le terme doit être distingué, au sens strict, de certains de ses synonymes les plus proches: «Il arrive assez souvent qu'on emploie le mot tableau en parlant d'une fresque, d'une miniature, d'un pastel, et, en général, de toute composition peinte à l'aide d'un procédé quelconque et sur une matière quelconque; mais, dans son acception la plus usitée et la plus juste, ce mot sert à désigner une peinture mobile, exécutée sur une toile ou sur une feuille de bois, de métal, de marbre, d'ardoise, etc., et entourée d'un cadre» (Larousse 1875: 174). Sous cet angle, ce qui fait le tableau serait la combinaison de la mobilité (la représentation pouvant être décrochée, déplacée et réinstallée où qu’on veuille) et du cadre (l'entourant et la délimitant). Cependant, au sein d'un recueil de poèmes, la connotation première d'un titre comme "Tableaux parisiens» ne saurait concerner les autres arts (théâtre ou peinture) : elle renvoie d'abord et avant tout à une tradition proprement littéraire qui remonte à la fin du XviII ${ }^{\mathrm{e}}$ siècle et dont l'apogée se situe dans les années 1840 , celle du "Tableau de Paris», que d'ailleurs Karlheinz Stierle a retracée (1980: 351). Initiée par Diderot et Louis-Sébastien Mercier, et en déclin lorsque Baudelaire publie ses Tableaux parisiens, elle se caractérise par un programme commun: dépeindre la modernité (Stierle: 345-352). Il est remarquable que, selon Stierle (352), parmi les poèmes de cette section des Fleurs $d u$ Mal les seuls qui renouvèlent la tradition du «Tableau de Paris» sont ceux qui intègrent le recueil avec l'édition de 1861.

4. On connaît le soin que Baudelaire a mis à organiser la succession des poèmes dans son recueil afin de le rythmer au moyen d'une séquence cohérente; Scott Carpenter rappelle (2006: 61) que l'auteur des Fleurs du Mal s'en est confié à Alfred de Vigny en décembre 1861 (Baudelaire, Correspondance: t. II, 196). 
mortel saute et se pâme» («Danse macabre»: 98). Qu'en dire, sinon que la froideur du cours d'eau familier est opposée à la chaleur du fleuve sacré de l'Inde? Lui aussi, du reste, est par deux fois nommé dans les Tableaux parisiens. Le privilège n'est donc pas des plus exclusifs. S’il est vrai que, comme l'a remarqué Patrick Labarthe à propos de ces deux vers, la "vision d'une humanité unifiée, au-delà des différences climatiques, [...] confère à la Seine le statut d'un fleuve sacré, témoin impassible du fol aveuglement des humains» (Labarthe 1995: 45), on se gardera d'y voir une unité gommant les différences ou une impassibilité excluant l'intervention du fleuve dans l'activité humaine. Car le texte de Baudelaire, tout en soulignant l'universel, détaille le particulier à travers l'antithèse ${ }^{5}$. S'atteste en ces vers l'esprit romantique qui, entiché d'exotisme, fait la part belle au lointain et montre l'ici-présent en morne repoussoir. De même, cette juxtaposition poétique de deux fleuves aux antipodes - sans manquer d'élargir le propos du particulier au général - évoque des valeurs extrêmes du domestique et de l'étranger. Rapprocher la Seine et le Gange de la sorte, c'est, plus encore, confronter le quotidien et l'inusité, le commun et l'extravagant, l'accessible et l'excentré. Sont mesurés l'un à l'autre l'espace de fréquentation coutumière - celui du flâneur exerçant sa "fantasque escrime » sous «Le Soleil» (83) - et le bout du monde - lieu dont rêve le voyageur éprouvant «L'invitation au voyage» (53-54). Partant, on s'autorisera à gloser qu'au sein de cette «Danse macabre» s'esquisse en filigrane le rôle maritime de la Seine, laquelle à l'époque est la principale et presque unique voie de transport et de communication entre la Capitale et les contrées éloignées ${ }^{6}$. Ces remarques étant faites, convenons que la présence du cours d'eau, bien que nominative, reste somme toute anecdotique.

La seconde occurrence du mot "Seine» dans ces dix-huit poèmes est du même acabit. Puisqu'elle survient à la fin du "Crépuscule du matin", c'est sur elle que se clôt cette section des Fleurs du Mal:

L'aurore grelottante en robe rose et verte

Avançait lentement sur la Seine déserte,

Et le sombre Paris, en se frottant les yeux,

Empoignait ses outils, vieillard laborieux. (104).

Baudelaire situe aux abords du fleuve la rencontre entre l'aurore et Paris personnifiés, tout ensommeillés et s'arrachant chacun péniblement à ses rêves nocturnes. Coup de chapeau à cette trouée qu'ouvre la Seine au milieu des hautes maisons de la ville moderne (Citron 1961: t. II, 180), à cette difficulté qu'ont les rayons du Soleil matinal, presque horizontaux, de pénétrer l'enchevêtrement des rues étroites. Souvent l'astre du jour n'apparaît au Parisien matinal qu'aux abords du cours d'eau, perçant entre les édifices séparés par le fleuve, se pailletant dans l'onde pour gagner en splendeur. Lieu de convergence, de réunion, dira-t-on. À tort, car en relisant de près les quatre vers on constate que cette concession à la réalité matérielle de l'endroit implique au contraire une distance: quand il pose ainsi la ville anthropomorphisée debout sur le cours d'eau désert, le poète accentue, sur le plan symbolique, la dissociation entre la «Fourmillante cité» («Les sept vieillards»: 87) et la rivière inhabitée qui la traverse. Le Fleuve

5. Baudelaire n'est pas le premier à confronter les deux fleuves. Balzac dans Le Contrat de mariage (1842) prêtait à Henri de Marsay une réplique jouant de la même opposition, destinée à dissuader Paul de Manerville de refaire sa vie à Calcutta: «Au lieu d'aller te mariner dans les Indes, il est beaucoup plus simple de naviguer de conserve avec moi dans les eaux de la Seine» (Balzac cité par Citron 1961: t. II, 87). Les valeurs de la figure sont cependant transformées: tout en jouant de l'universalité des cours d'eau, Baudelaire en souligne les contrastes.

6. «La navigation intérieure est le principal élément de la prospérité publique», lit-on le 13 juin 1837 dans les pages du quotidien Le Siècle. Aussi, le fleuve joue un rôle commercial prépondérant qui fait que, jusqu’à la fin du siècle, Paris demeure le premier port de France (Gaillard 1982: 13). 
est un, la Cité est autre; l'un et l'autre se croisent en étrangers à tel point de l'espace physique. À croire que la Seine serait isolée de Paris, n'en ferait pas partie. C'est une clairière, une étendue neutre, différente, interstitielle... un intervalle dans l'urbanité, scindant le tout de part en part. Elle n'a peut-être de parisien que son rôle de plaine fluviale, site vide accueillant la ville comme un réceptacle à remplir. Or, ce qu'on goûte dans un plat, c'est le mets; non la faïence.

À ce stade préliminaire de l'enquête, il faut convenir que la Seine fait figure, au mieux, de détail géographique, de décor, de notation pittoresque. Même allégorisée elle ne semble pas intéresser outre mesure le poète des Tableaux parisiens, lui qui n'en a que pour les hauteurs, l'élévation «Et les grands ciels qui font rêver d'éternité» (82), comme en témoigne la strophe d'ouverture de «Paysage», premier poème de la section: "Je veux, pour composer chastement mes églogues,/Coucher auprès du ciel, comme les astrologues» (82), prévient-il. Si «Les deux mains au menton, du haut de [s]a mansarde», le poète porte quelquefois son regard des hauteurs vers le bas, ce sera seulement afin d'incliner son front sur son pupitre, "Pour bâtir dans la nuit [s]es féériques palais», pour "rêve[r] des horizons bleuâtres,/ Des jardins, des jets d'eau pleurant dans les albâtres" (82). S’il se penche de son perchoir, ce sera donc pour écrire et imaginer des tableaux, non pour contempler ou décrire un cours d'eau.

\section{Paysages parisiens}

Ces discrètes évocations pourront laisser déçu l'amateur de marines. La présence du fleuve parisien est ténue, quand on pense au traitement que lui ont réservé certains des héritiers de Baudelaire, Verlaine en tête, avec son "Nocturne parisien", qui débute par ces mots: "Roule, roule ton flot indolent, morne Seine» (Poèmes saturniens: 83). On pense aussi à Jules Laforgue, dont le premier recueil de vers, Les Complaintes, commence sur les quais parisiens, parmi les bouquinistes ("À Paul Bourget»: 35), quand la piqûre d'Épicure l'enjoint à "passe[r] la Seine, en flânant», ravi, béat dans le "plaisir tout nouveau " de "voir se briser l'eau» contre l'arche d'un pont («Épicuréisme»: 178); on songe encore à Rimbaud, dont le «Bateau ivre» appareille "guidé par les haleurs» du fleuve, avant de se débrider en mer (122); ou même, plus tard, au «Pont Mirabeau» de Guillaume Apollinaire. Tout indique qu'on serait en droit de s'attendre à trouver, parmi cette petite vingtaine de Tableaux parisiens, une vue du fleuve, quelle qu'elle soit.

La vaste étude qu'a menée Pierre Citron sur La Poésie de Paris dans la littérature française de Rousseau à Baudelaire conforte la déception qu'on peut éprouver devant les timides mentions de la Seine que présente cette section des Fleurs du Mal. Car le libellé "Tableaux parisiens" signale chez Baudelaire "une volonté de saisir [...] le Paris objectif» par une attention spéciale portée "à la réalité extérieure et à la netteté du trait» (Citron 1961 : t. II, 341). Ce souci accru de la matérialité d'une ville dont la fluvialité est un aspect primordial avait toutes les chances de déboucher sur des tableaux de la Seine, puisque le silence qui s'était fait autour du fleuve urbain chez les premiers romantiques durant l'Empire et la Restauration (Citron 1961: t. I, 421) était levé depuis une vingtaine d'années quand Baudelaire a composé ses poèmes (Citron 1961 : t. II, 177-1807). La tendance s'étant inversée, le fleuve allait prendre de plus en plus de place dans la poésie de Paris; il était par ailleurs toujours resté, pour la plupart des romantiques, «un des éléments les plus nobles de Paris» (Citron 1961: t. I, 422). Ceci

7. Les travaux d'Antoine Fongaro attestent hors de tout doute que le vieux mythe de la création ex nihilo ne s'observe pas davantage chez Baudelaire qu'ailleurs: sans enlever quelque mérite que ce soit à l'auteur des Fleurs du Mal, il faut reconnaître que même les plus belles, les plus modernes et jusqu'aux plus «surréalistes» de ses images résultent d'emprunts et non «d'une création radicalement originale» (Fongaro 1988: 36). 
se vérifie notamment chez le "poète impeccable» à qui Les Fleurs du Mal sont dédiées (Baudelaire, Les Fleurs du Mal: 3). En effet, Théophile Gautier dès le "Soleil couchant" qui clôt son premier recueil en 1830, s'arrête, «En passant sur le pont de la Tournelle, un soir», aux beautés qui s'étendent devant lui «à faire baisser la paupière»:

[...] - l'air était doux; les eaux

Se plaignaient contre l'arche à doux bruit, et la vague

De la vieille cité berçait l'image vague (Gautier, «Soleil couchant»: 97).

Puis, développant sa vision avec plus d'ampleur encore en 1833 avec le poème "Notre-Dame ${ }^{8}$ ", Gautier trouve aux abords de la Seine "des tableaux ardents à vous brûler les yeux" (271) lorsque la lumière «Dans la moire du fleuve enchâsse cent miroirs» (274). Quand on connaît "le goût de Baudelaire pour les "sources" " et "son utilisation de l'espace marin, qui [...] reprend des figures bien connues à l'époque», comme l'indique bien Nelson Charest (2008: 98), on reste surpris.

Mais peut-être la Seine est-elle présente dans les Tableaux parisiens de Baudelaire sans être nommée? Reprenons par exemple le premier des dix-huit poèmes. À l’origine, il s'intitulait «Paysage pari$\operatorname{sien}^{9}$ » : si mention est faite d'un fleuve dans ce "paysage», on pourra en inférer qu'il s'agit bien de la Seine, puisqu'il n'existe pas d'autre fleuve à Paris. Or, le poète n'évoque pas un, mais des fleuves, qu'il contemple au début de la deuxième strophe:

Il est doux, à travers les brumes, de voir naître

L'étoile dans l'azur, la lampe à la fenêtre,

Les fleuves de charbon monter au firmament

Et la lune verser son pâle enchantement. (Les Fleurs du Mal: 82).

Ces coulées de suie à la progression ascendante font certes, sous l'œil du poète, danser «Les tuyaux, les clochers, ces mâts de la cité» (82), mais elles ne renvoient point à la coulée horizontale que recherche notre lecture, celle qui serpente à travers la vallée parisienne. Tout au contraire, ces fumées présentées sous la forme de vapeurs berçant les mâts d'un grand navire tendent à porter les eaux au firmament et, avec ce détournement métaphorique du mot «fleuve» pluralisé, se trouvent plutôt à escamoter la présence de la Seine derrière leur panache.

Et pourtant, le fleuve ne s'absente pas tout à fait de ce "Paysage parisien", puisqu'y sont évoquées obliquement les armes de Paris: l'image de "ces mâts de la cité» (82) figure la ville comme une nef voguant sur les flots, à l'instar du blason officiel, qui représente Paris sous la forme d'un vaisseau marchand balloté par une étendue d'eau agitée, le tout surplombé d'un chef bleu foncé, parsemé d'emblèmes d'or. Si, en effet, pour l'insurgé de février et juin 1848 (Pichois 1975a: XXXIII-XXXIV), «Il est doux, à travers les brumes, de voir naitre / L'étoile dans l'azur» (Baudelaire, "Paysage»: 82), c'est peut-être que, depuis la fin de la Restauration, la pression républicaine a fait remplacer les fleurs de lys qui ornent traditionnellement la partie supérieure du blason (symboles du droit divin des Rois de France) par des pentacles sur fond indigo (Declerck 2007: 67-77; Coëtlogon 1874: 160-164). Ce moderne ciel étoilé coiffant les armoiries de Paris est une raison de plus, pour le poète baudelairien,

8. Ce poème fut recueilli en 1838 dans La Comédie de la mort, volume considéré comme l'une des lectures les plus marquantes pour le jeune Baudelaire (Citron 1961 : t. II, 344).

9. C'est sous ce titre que le poème fut publié d'abord dans Le Présent (15 novembre 1857), avant de perdre l'épithète devenue inutile lorsqu'il fut placé en tête des Tableaux parisiens. 
de se tourner vers le firmament et, corollairement, de délaisser le mouvant support sur lequel flotte invariablement le navire ${ }^{10}$.

Dans les Tableaux parisiens, même une occurrence du mot «fleuve» au singulier n'est pas garante de l'évocation du cours d'eau qui scinde la ville en deux rives. Le prouve l'exemple du poème «Les Petites Vieilles", à propos desquelles le poète s'exclame: «Toutes auraient pu faire un fleuve avec leurs pleurs!» (90).

Ces quelques observations conduisent à une hypothèse: la Seine serait-elle trop familière, trop bien connue du poète et des Parisiens en général pour stimuler l'imagination de celui qui, en définitive, préconise de plonger «Au fond de l'Inconnu pour trouver du nouveau!» ("Le voyage»: 134). Néanmoins, la question reste entière: où est la Seine dans les Tableaux parisiens? Existe-t-il dans les Tableaux parisiens une occurrence où le mot «fleuve» renvoie bel et bien à la Seine? Ce semble bien le cas.

\section{"Le cygne»}

Il arrive une fois dans les Tableaux parisiens que «fleuve» désigne la Seine - mais c'est de manière passablement détournée. Après tout, quoi de plus convenable que des détours, quand il s'agit d'une rivière aussi sinueuse que celle-là? L'occurrence se trouve dans "Le cygne», qui, remarque Lowry Nelson Jr. (1961: 338), est le plus topographiquement précis des poèmes de Baudelaire. Cette concrétude sert la dimension critique et polémique d'un texte dédié à Victor Hugo, qui s'est exilé de la dictature de Napoléon III rénovateur du vieux Paris (Nelson 1961: 340); elle sert aussi, inversement, à étayer le sentiment d'expatriation qu'éveille en Baudelaire une ville moderne marquée par ce que Jean Starobinski appelle le «retrait de la réalité (si directement attesté par le fait historique des destructions opérées dans le paysage urbain)»(1989: 74-75). "Paris change!», s’écrie le poète (Baudelaire, "Le cygne»: 86): l'haussmannisation bat son plein. Or la Seine constitue l'un des points focaux de la vaste rénovation de la ville.

La rivière ayant été depuis peu promue, dans les mentalités, au rang d'«élément essentiel de l'architecture urbaine» (Beaudouin 1989: 51), quoi de plus normal qu'elle fasse l'objet d'améliorations esthétiques autant que pratiques? Le préfet de la Seine lui-même considère que la réfection du pont Notre-Dame a marqué «[s]es débuts dans les Grands Travaux Publics» (Haussmann, 1893: 17). Pour

10. Soulignons que le semé d'étoiles jaunes n'est pas exclusifà la République, puisqu'il s'impose d'abord sous la Monarchie de Juillet, qui préconise officiellement de "faire disparaître les fleurs de lys partout où l'on pourra le faire sans dégrader les monuments publics" (note de Louis-Philippe communiquée aux journaux en 1831 [citée par Declerck: 69]). D'ailleurs, les étoiles ont continué d'illuminer le chef bleu de l'emblème parisien durant les débuts du Second Empire, et ce, jusqu'à la fin de 1853, lorsqu'à l'initiative d'Haussmann le régime décréta une exception afin que les traditionnelles fleurs de lys soient rétablies: «Il repoussa les étoiles, qu’on avait introduites depuis quelques années dans le chef de l'écu et qui, ne rappelant aucun souvenir historique, semblaient n'être là que pour y remplacer, par une figure d'égale grandeur, la fleur de lys, ancien attribut royal», raconte Anatole de Coëtlogon (1874: 163). Ajoutons d'autre part que, si Baudelaire «a vécu les Journées de 1848 avec une conviction réelle», comme le signalent Claude Pichois et Jean-Paul Avice, «il est plus un révolté [...] qu’un révolutionnaire»: après le Coup d'État de 1851, sa rébellion se tournera "contre la religion du progrès matériel» (2004: 87). Par conséquent, le fait historique avec lequel résonnent ces vers du poème "Paysage» s'avère moins une critique voilée d'un régime néo-napoléonien dont Baudelaire, finalement, s'accommode assez bien, malgré la censure et la persécution encourues par ses Fleurs du Mal (Pichois 1975a: XXXV), que l'évocation indirecte d'un détail héraldique ayant pu, naguère, susciter l'agrément du révolutionnaire et ne suscitant plus, désormais, que la mélancolie du poète ressassant le souvenir de ses espoirs trompés. 
ce pont, comme pour les nombreux autres ouvrages fluviaux qui dans la foulée allaient être rénovés, remplacés ou carrément supprimés, il s'agissait de faciliter la navigation commerciale en abaissant le niveau et la vitesse de l'eau ${ }^{11}$, au moyen de l'élimination de quantité d'obstacles qui entravaient le fleuve et en réduisaient la section d'écoulement (Beaudouin: 54-55). À partir de 1854, on entreprit de diminuer la largeur des piles des ponts ou leur nombre, on démolit ou ferma plusieurs des pompes qui fournissaient l'eau aux Parisiens, et la plupart des quais furent "reconstruits, soit rectifiés et rehaussés", précise l'historien Marc Gaillard (2002: 50). Ce titanesque projet de normalisation orthogonale et d'élévation des berges de la Seine visait à brider celle-ci dans la pierre, pour la tenir à certaine distance des activités de la ville; la rivière put paraître diminuée aux citadins mieux habitués de la fréquenter, en particulier ceux affectant de mépriser le " progrès $^{12}$ ».

Toujours est-il qu'au premier vers de la première strophe du "Cygne» s'offre, ne serait-ce que laconiquement, voire subrepticement, une image de la Seine telle que la voit le poète:

Andromaque, je pense à vous! Ce petit fleuve,

Pauvre et triste miroir où jadis resplendit

L'immense majesté de vos douleurs de veuve,

Ce Simoïs menteur qui par vos pleurs grandit,

A fécondé soudain ma mémoire fertile,

Comme je traversais le nouveau Carrousel. (Les Fleurs du Mal: 85).

Pour Jean Starobinski, le «Je pense» qui sera réitéré maintes fois dans la seconde moitié du poème non seulement redouble celui du premier vers, illustrant alors la résurgence (avec variations) du passé dans l'esprit présent du poète, mais aussi «atteste, en appelant, de nouvelles images, la fécondation opérée en lui par le "petit fleuve" qui a recueilli les "pleurs" d'Andromaque» (Starobinski 1989: 60). En effet, si ce "Pauvre et triste miroir", devant lequel sangloter, paraît figé, mort, comme le sont toutes les vanités, il déclenche pourtant une déferlante. Comment s'opère un tel prodige? L'eau en stase conduisant à l'"extase» de la veuve (Baudelaire, "Le cygne»: 86) est celle d'un fleuve. Ce n'est pas une eau morte, mais une eau vive, mouvante: l'image qu'elle projette vers l'œil est myriade de reflets déformants. Piètre miroir donc, "pauvre», «triste», «menteur», et pour cela (ou malgré cela) fécond. Cette eau, augmentée de l'épanchement personnel qu'elle a elle-même suscité par le détour de «l'immense majesté", eau "déceptive» selon le mot de Starobinski (1989: 70), fait retour sur elle-même ${ }^{13}$. Et, dans l'énergie cumulée de sa crue, elle porte vite au débordement cette Andromaque qu'on trouvera bientôt penchée sur ses chagrins, «en extase courbée» (Baudelaire, «Le cygne»: 86).

Puisque le poème entier semble, jusque dans ses plus discrètes minuties (structure bipartite, répétitions lexicales, renvois internes, échos référentiels), construit pour faire honneur au mot miroir du deuxième vers (Starobinski 1989: 58-59), il paraît légitime, pour mieux voir les choses, de tenter de

11. Des crues hivernales ou printanières se produisaient presque annuellement, entraînant chaque fois leur lot de dommages matériels, mais c'est surtout le spectre des crues plus sévères, par exemple celles de 1802, de 1836 et de 1844 , qui motivait les travaux des ingénieurs Belgrand et Alphand, délégués par Haussmann.

12. À cette période, Baudelaire se vante de «faire frémir [...] les amateurs du progrès» (lettre à Charles Asselineau du 20 février 1859) et de proposer des poèmes regorgeant de "plaisanteries contre le progrès» (lettre à Maxime Du Camp du 23 février 1859), notion phare du Second Empire devenue la cible privilégiée du dandy (Baudelaire, Correspondance: t. I, 553 et 554).

13. Curieusement, dans les Tableaux parisiens, l'eau est moins souvent celle des fleuves que celle des veuves, témoin la «Passante» dont on ignore où elle «fuit» avec son "grand deuil» (Baudelaire, «À une passante»: 92-93). 
renverser le point de vue. Quittons celui de la veuve et revenons à celui du poète dont le regard a été accroché par le fleuve. On constatera que l'eau n'est pas seule à déformer les reflets. Évidemment, si le poète passe «devant [1]e Louvre» (Baudelaire, «Le cygne»: 86), dont le séculaire projet de réunion avec le palais des Tuileries vient d'être réalisé sous Louis-Napoléon et inauguré le 14 août 1857 (Gaillard, 2002: 13); si le poète est en train de franchir ce quartier du Carrousel récemment rasé dans le cadre des grands travaux de réaménagement du Second Empire, alors le "petit fleuve» qui a fait déferler ses souvenirs en accrochant son regard ne peut être autre que la Seine (Nelson: 337). L'appeler Simoïs, c'est dire combien sa vue vous fait penser à autre chose. Et c'est le désigner par son reflet, ce qui revient à le dédoubler, à l'assimiler à un autre, à un semblable, à un frère - siamois bien sûr, comme le suggère déjà la graphie du mot. C'est illustrer la façon dont la réalité matérielle de Paris dans "Le cygne» fait signe vers autre chose. Perçue par celui qui la regarde, elle imprime en lui une image d'elle-même autre qu'elle-même, étant travestie par l'esprit du poète, chargée par lui de significations connexes, d'associations plus ou moins libres, de références personnelles, de compréhensions intimes. N'est-ce pas tout à fait cela, "féconder» une mémoire "fertile»? Non pas se remémorer quelque chose (ce serait éveiller un souvenir exact), mais littéralement inventer une réminiscence: créer à partir d'un matériau psychique quelque chose d'inédit et d'inauthentique mais qui, étant engendré par la mémoire, peut prendre dans l'esprit valeur de remémoration, c'est-à-dire de réalité avérée ayant réellement existé naguère. Pour le sujet percevant le stimulus ainsi faussé par le cristal de sa pensée, impossible de distinguer le véridique du fabriqué. Tout est vrai.

En l'occurrence, la pensée suscitée par la Seine est celle du Simoïs, fleuve chanté par Virgile dans L'Énéide. Il s'agit d'un souvenir littéraire ${ }^{14}$, allusion intertextuelle particulièrement riche et pénétrante, dont les comparatistes ont légitimement fait un cas d'école (Nelson: 332). Selon la mythologie romaine, le Simoïs prend sa source au Mont Ida et descend dans la plaine de Troie, à l'extrémité occidentale de ce qui se nomme aujourd'hui l'Anatolie (péninsule turque). Mais déjà chez Virgile ces coordonnées géographiques sont une fausse piste, et c'est en cela que le Simoïs est menteur une première fois (on verra qu'il l'est plusieurs fois) : l'épisode de L'Énéide auquel fait allusion Baudelaire, parmi les plus célébrés du poète latin ${ }^{15}$, se déroule non pas en Troade mais dans l'Épire, une région à la périphérie nord de la Grèce, sur la côte ouest de la péninsule des Balkans, à des milliers de kilomètres de la Troie véritable (celle d'Hector, dévastée lors de la guerre relatée dans L'Iliade). D'ailleurs, les traducteurs du «Falsi Simoentis ad undam ${ }^{16}$ " de Virgile hésitent entre diverses formules: on lit «nou-

14. Cela est courant chez Baudelaire, en particulier pour tout ce qui touche à la capitale; d'après Pierre Citron: «Au Paris réel se superposent pour lui et le Paris du mythe dans son ensemble, avec son langage établi, et les Paris particuliers des poètes auxquels il doit tant: ceux de Gautier et de Banville, avant tout esthétiques, celui de Hugo, très divers mais à dominante épique, et, plus profondément, celui si riche de Balzac» (1961: t. II, 344).

15. Il faut voir avec quel enthousiasme Jacques Delille commente la scène dans sa célèbre traduction de L'Énéide (rééditée de multiples fois dans la première moitié du XIx ${ }^{e}$ siècle, entre autres par Furne) : "Cet épisode est un de ceux qui font le plus d'honneur à l'imagination et à la sensibilité de Virgile. Il suppose qu'Andromaque, épouse involontaire de Pyrrhus, avait eu le bonheur, après la mort de ce héros, d'épouser le jeune Hélénus, fils de Priam, et devenu, par la mort du fils d'Achille, l'héritier de son empire et de sa femme. Dans cette nouvelle situation, elle était encore moins la femme d'Hélénus que la femme d'Hector: elle avait élevé deux autels où venaient couler ses larmes. Le poëte ne dit pas, mais le lecteur devine aisément que, de ces deux autels, l'un était consacré à son fils, et l'autre à son époux. C'est peu : elle avait, dans ce coin de l'Épire, imité tous les objets de ses regrets, Ilion, le Simoïs, le Scamandre; et, par cette douce ressemblance, elle trompait la douleur de ses pertes, et les rigueurs de son exil. C'est encore une idée qui, quoique naturelle et touchante, ne serait point venue au bon Homère [...]» (Delille 1821 : 374-375).

16. Ces mots figuraient en épigraphe du poème lorsque Baudelaire le publia la première fois, dans La Causerie du 22 janvier 1860 (Pichois 1975b: 1008). 
veau Simoïs» (Virgile traduit par Delille [1821: 417]), "faux Simoïs» (Virgile traduit par Auguste Desportes [1862: t. III, 34]), ou même «cours d'eau qui imitait le Simoïs» (Virgile traduit par André Bellessort [1925-36: t. I, 80]). Un tel éventail d'énoncés atteste la gamme de significations qu'un lecteur aussi habile que Baudelaire ${ }^{17}$ pourrait donner à ce détail du texte latin. J'en relèverai trois. Soit il s'agit d'une rivière de l'Épire ressemblant en quelque manière au Simoïs authentique et rappelant à la veuve les temps passés par une similitude qui gomme la distance tout en signalant l'écart irrémédiable entre l'original et l'ersatz; soit il s'agit d'une rivière quelconque, rebaptisée Simoïs par Andromaque, en souvenir du véritable Simoïs coulant près de Troie, qui manque tant à la veuve exilée; soit, encore, il s'agit d'un cours d'eau fabriqué par Andromaque, ou à tout le moins remodelé par elle de façon à lui rappeler l'original, et par cette ressemblance contrefaite ressusciter le passé chéri pour tromper le sentiment indélébile de la perte.

L'une ou l'autre manière d'appréhender le texte de Virgile s'accordent avec l'attitude que Baudelaire prête au je poétique dans cette première strophe du "Cygne», lui qui d'une première pierre jetée à la Seine fait deux coups, en rebaptisant le fleuve parisien et le traitant de menteur. C'est lamenter l'hausmannisation, c'est lancer un "pavé sec» (Baudelaire, «Le cygne»: 86) dans la mare poudreuse du Second Empire triomphant qui nettoie à sec (à sac, dirait sûrement Baudelaire songeant aux barricades de 1848); c'est grommeler devant un régime voué à l'éradication des "baraques», des "herbes», du «bric-à-brac confus» (86); c'est jeter à la mer tarie du progrès orthonormé non une bouteille ou un galet - succédanés de ces "gros blocs verdis par l'eau des flaques» (86) -, mais un de ces «blocs» massifs de la huitième strophe qui sont la clé de voûte des "palais neufs" (86). C'est même, avec amertume, botter «Sur le sol raboteux" une motte de souvenirs "plus lourds que des rocs», dans l'espoir « ridicule et sublime» de la voir éclabousser l'Empire lorsque, malencontreusement, elle atterrit au milieu d'un «ruisseau sans eau» (86). S'accorde avec cette lecture le fait, relevé par Jean Starobinski, que sur le plan des sonorités le poème est marqué par un grand nombre de "groupes de plosives + liquides» (1989: 67), qui miment phonétiquement le contact brutal du rocailleux et de l'aqueux, sur fond d' "assèchement» généralisé (1989: 66).

Dans «Le cygne», la Seine "triste miroir» apparaît petite et calme, faible, dégradée ${ }^{18}$. Elle reste néanmoins toute-puissante dans la mesure où elle renvoie à l'individu sa propre image (déphasée), déclenchant un vaste enchaînement de réminiscences, d'analogies et d'inventions. Si la métaphore attendue de la "source» d'inspiration poétique s'en trouve déployée à nouveaux frais (Nelson: 337), elle est dévoyée: l'irrigation naturelle que procure un cours d'eau à ses territoires riverains, dans ce nouveau Paris, n'arrose que l'esprit «fertile» du poète, au point de tarir la contrée. En résulte une réflexion - reflet de soi - qui est trompeuse, "menteuse» à maints égards, comme nous en avons convenu. Elle l'est aussi en ce qu'elle renvoie à l'individu l'image de ce qui n'existe plus: voir son reflet est invariablement une invitation à constater combien l'on a vieilli et à entreprendre le voyage intérieur du souvenir, pour mieux mesurer le fossé qui sépare le maintenant du jadis. Menteuse, elle l'est d'une autre manière encore puisque, comme l'a remarqué Lowry Nelson Jr. (1961: 337), l'identification

17. Corinne Saminadayar-Perrin (2001) a éloquemment illustré le rôle capital qu’eurent les succès de Baudelaire écolier dans ses cours de poésie latine sur son œuvre ultérieure.

18. Tout le premier mouvement du poème tend vers ce déclin: «Le "Simoïs menteur" est une image dégradée du fleuve qui coulait dans la terre du "grand époux". Puis, dans ce qui deviendra l'arrière-fond spatial de l'apparition du cygne, il ne reste que "l'eau des flaques". La dégradation se poursuivra lorsque, sous les "pieds palmés" du cygne, ne subsistera plus qu'un "ruisseau sans eau". La dégradation n'est pas seulement, au sens étymologique du terme, la réduction au trivial, mais encore et surtout le tarissement [...]» (Starobinski 1989: 66). 
de la Seine au Simoïs assimile implicitement le Paris de Baudelaire, celui de toutes les dégradations (morales ou physiques), à la "petite Troie» de Virgile, qui déjà était un pâle substitut de la grande Troie d'Homère. D'Anatolie en Épire puis en Île-de-France, les relocalisations s'enchaînent, chaque fois plus lointaines de l'original et moins fidèles à lui, et chaque fois l'avilissement s'accuse. Ce qui est vrai aux plans de la géographie et de l'urbanisme l'est aussi au plan littéraire, attendu que les diverses allusions inscrites au sein du poème "correspondent à des âges de la poésie» (Starobinski 1989: 58). Le point terminal de cette triple histoire est le moment présent: celui, poétique, de «l'invention moderne» (Starobinski 1989: 58); celui, historique, du constat que «Le vieux Paris n'est plus» (Baudelaire, «Le cygne»: 86); celui, topographique, du regard dépréciatif posé par le poète sur un fleuve récemment dénaturé par les ingénieurs haussmanniens. Tant et si bien que ce cours d'eau familier peut soudainement paraître «pauvre», «triste» et "petit» (Baudelaire, «Le cygne»: 85) à l'œil exigeant de celui qui, s'étant exilé à Honfleur en 1859 pour créer de «[n]ouvelles Fleurs du Mal», s'autoproclame «ennemi de [s]on siècle» (Baudelaire, Correspondance: t. I, 568).

Est-elle chétive, la Seine éminemment parisienne de ce "cygne»? Le poème ayant été composé dans la foulée du séjour au port de mer, là où l'embouchure devient océan ${ }^{19}$, on supputera qu'au retour en ville elle a pu sembler amoindrie. À la différence du petit Simoïs de l'Épire, doublement menteur parce que gonflé des larmes d'Andromaque (Nelson 1961: 337), la Seine, elle aussi transformée par l'intervention humaine, n'irrigue pas son environnement immédiat, dont la stérilité accable le grand oiseau qui étouffe dans le "sombre ouragan" de "poudre» produit par «la voirie" à cette "heure où [...] le Travail s'éveille» (Baudelaire, "Le cygne»: 86). C'est au poète qu'il reviendra d'entonner le proverbial chant du cygne ${ }^{20}$, prenant le relai du langage muet accusateur qu'orchestrent, en deuxième partie du poème, les "gestes fous" de ce volatile tendant la tête "Vers le ciel ironique et cruellement bleu, /[...] Comme s'il adressait des reproches à Dieu!» (86).

Convenons que, tout en étant modeste sur le plan matériel, cette Seine enrégimentée par l'industrie nouvelle fascine par ses virtualités. N'a-t-elle pas su tirer une larme du poète au premier coup d'œil? Elle a éveillé chez lui le regard désormais aux aguets, a exacerbé sa sensibilité aux mutations de la vieille ville, a suscité l'acuité accrue au temps qui passe et à la modernité qui cherche à s'installer sur cette table rase. Sans remettre en cause la mauvaise humeur que peut avoir générée cette flânerie en bord de Seine, il faut avec Gérard Gasarian souligner que «Baudelaire se montre surtout sensible à la dynamique du Paris en chantier, à la transition entre l'ancien et le nouveau " (1995: 65). On peut dire que le fleuve adopte alors un rôle qui lui est familier en littérature: celui de gigantesque clepsydre où l'on voit s'écouler les eaux du siècle.

\section{"Rêve parisien »}

Or la Seine resurgit avec un semblable rôle, innommée encore, dans "Rêve parisien", l'avant-dernier poème de la section. De même que dans le "Cygne» règnent les perpendiculaires de la pierre taillée et le treillis droit de la "cage» ou des "échafaudages», le "Rêve parisien» est dominé par les

19. La lettre envoyée à Nadar en date du 14 mai 1859 fait état d'un aller-retour que Baudelaire allait devoir effectuer prochainement entre Honfleur et Le Havre (Baudelaire, Correspondance: t. I, 573). Le trajet impliquait une traversée de l'estuaire de la Seine en bateau (Pichois 1973: t. I, 990). À peine une ou deux semaines plus tard (Baudelaire, Correspondance: t. I, 582-583), Baudelaire envoya à Jean Morel, directeur de la Revue française, une première version des «Sept vieillards", poème auquel j'aurai l'occasion de revenir.

20. Encore une référence qui nous ramène à l'Antiquité (par la figure de Socrate, notamment). 
traits rectilignes ${ }^{21}$ que l'homme confère à la matière quand il la travaille sous «la forme d'une ville " (Baudelaire, "Le cygne»: 85-86). De quoi susciter la mélancolie: Jean-Pierre Richard a montré la prédilection baudelairienne pour "la sinuosité des lignes», par opposition aux traits plus «secs» et plus «idéaux» de l'arabesque, trop décorative, ou de la droite, trop dure (Richard 1955: 147); l' «amour du spontané» baudelairien mène au rejet de la «ligne systématique», si régulière, si prévisible (Richard 1955: 147). Cependant, avec "Rêve parisien", texte datant de la même année que "Le cygne", la perspective est diamétralement inversée. Le poète ne pleure plus la disparition des rondeurs du "lac natal», ni celle des serpentements naturels ou autres formes d' "extase courbée» (Baudelaire, "Le cygne»: 86). Baudelaire écrira deux ans plus tard «Le coucher du soleil romantique", façon performative de signer par décret la fin d'une esthétique au moyen d'un hommage tenant pour admis que le déclin est en cours, sinon achevé. Mais déjà avec les octosyllabes de son "Rêve parisien", dédié au Peintre de la modernité Constantin Guys, l'auteur des Fleurs du Mal se trouve à bannir la Nature amie, «Le végétal irrégulier,/ Et, peintre fier de [s] on génie», il savoure alors «dans [s] on tableau/ L'enivrante monotonie/ Du métal, du marbre et de l'eau» (Baudelaire, "Rêve parisien»: 101). Renversant les valeurs bucoliques que Victor Hugo exprimait en 1837 dans le poème "À Virgile», où l'on quitte prestement la ville «Qui, géante, [...]/ Presse un flot écumant entre ses flancs de pierre» (Hugo, " $\mathrm{A}$ Virgile»: 959), le poète baudelairien se fait le créateur d'une ville idéale mêlant l'Antiquité grécoromaine à la fantaisie onirique pour canaliser des eaux omniprésentes et multiformes. Qu'elle soit recueillie en «bassins», en «nappes» ou en «étangs dormants», conduite «Entre des quais [...] pendant des millions de lieues» ou versée «Dans des gouffres", figée en "D’immenses glaces» ou en «rideaux de cristal ", ou encore déchaînée en "cascades", en "cataractes pesantes " (Baudelaire, "Rêve parisien»: 102), l'eau est maniée, contenue, déployée: sa fougue naturelle, sinon matée, est sublimée en "flots magiques" par les "pierres inouïes» (102) que le génie humain sait façonner.

Tel est le propre des fluides. Se prêtant à tous les moules, ils adoptent la forme du contenant où on les coule. On rejoint là le comportement qu'avait la réalité matérielle extérieure dans "Le cygne»: façonnée par la psyché du poète, la perception d'un fleuve débouchait sur un autre. Mais c'est le $\mathrm{XIX}^{\mathrm{e}}$ siècle entier qui conçoit la pensée comme un fluide qui par la littérature (et ses intermédiaires: plume, encre, papier) s'extravase du cerveau de l'auteur à celui du lecteur. La métaphore pullule chez Balzac, lequel n'a de cesse de nous entretenir du «fluide particulier d'où s'élan[cent] nos Idées et nos Volitions» (Louis Lambert: 79). Elle n'est pas beaucoup plus rare chez Baudelaire ${ }^{22}$, bien qu'elle acquière dans Les Fleurs du Mal un sens légèrement distinct qui me paraît lié à la pratique de la versification. Le recueil offre plusieurs passages assimilant intimement l'esprit aux fluides, citons-en un: «Mon esprit, tu te meus avec agilité,/Et, comme un bon nageur qui se pâme dans l'onde,/Tu sillonnes gaiment l'immensité profonde» (Baudelaire, "Élévation»: 10). La configuration est particulière en ce que, là où le romancier fait du fluide la matière même de la pensée, le poète tend à montrer la pensée flottant sur le fluide ou mêlée à lui, bercée par lui, emportée avec lui ${ }^{23}$. On pourrait s'en tenir

21. En cela, l'image de Paris que Baudelaire dédie à Victor Hugo est aux antipodes du Paris gothique chanté en 1831 dans Notre-Dame de Paris.

22. Dès 1843, le jeune Baudelaire évoque en alexandrins la délicieuse sensation d'avoir «bu» la substance d'un «Livre voluptueux", empli de "sonnets» et de «stances» composant "un breuvage» autrement plus apprécié "en ces temps d'adolescences pâles» que, plus jeune, «l'enfant boit», lui, depuis «dix ans, l'âpre lait des études» ("À Sainte-Beuve»: 206-207).

23. On rencontre tout de même dans Les Fleurs du Mal quelques passages où l'imagerie est plus balzacienne: "Je te hais, Océan! tes bonds et tes tumultes,/Mon esprit les retrouve en lui» ("Obsession»: 75); "La mer est ton miroir; tu contemples ton âme/Dans le déroulement infini de sa lame, Et ton esprit n'est pas un gouffre moins amer» 
à relever que la fluidité l'emporte sur la solidité quand il s'agit pour Baudelaire d'évoquer la création poétique (Acquisto 2008-2009: 34). Reste que chez lui le fluide est davantage véhicule, moyen, intermédiaire, que matière poétique: il est vecteur de poésie. Raison de plus de se soucier de la forme qu'il empruntera, des contours qu'il épousera, du tracé qu'il suivra, des orientations qu'il procurera à la pensée. Travail d'ingénieur hydrologue, d'urbaniste ou... d' "architecte», comme dit le poète dans "Rêve parisien» (102). Travail de poète? Oui, car en poésie versifiée le vers, fréquemment rapproché de son homophone le ver (celui de l'ennui ou, plus souvent chez Baudelaire, celui du remords ${ }^{24}$ ), est aussi un verre ${ }^{25}$ : le poète y verse le fluide qui portera sa pensée vers ${ }^{26}$ son public. Il faut rappeler avec Scott Carpenter que l'étymologie du mot «renvoie depuis l'origine de la poésie à l'image d'une voie - le sillon creusé par la charrue" (2006: 56). Réceptacle autant que direction, le vers baudelairien donne à l'informe sa forme et son sens. L'eau pure du «Rêve parisien", sans couleur ni odeur, inerte aux sens, s'impose alors comme une matière des plus neutres, des plus polyvalentes et (nous le constaterons bientôt) des plus ambivalentes.

À l'évidence, le «Rêve parisien" de Baudelaire prétend emplir l'esprit du lecteur de «mouvantes merveilles» (103) : images inusitées qui, entrées en nous, «brill[eront] d'un feu personnel» (102). Que voit-on donc à la lecture de ce poème? Devant les «colonnades», les «escaliers» et les "arcades» (102) qui forment "ce terrible paysage» (101) baigné par les eaux que déversent "Des Ganges, dans le firmament» (102), se dessinent des structures accouplant, pour ainsi dire, le Parthénon de l'Acropole à l'Alhambra de Grenade. Et le poète de revendiquer la paternité de ce syncrétisme:

Architecte de mes féeries,

Je faisais, à ma volonté,

Sous un tunnel de pierreries

Passer un océan dompté. («Rêve parisien»: 102).

Sommes-nous bien à Paris? D'où vient toute cette eau? Quel est ce fleuve domestiqué par la puissance et l'ingéniosité de l'homme? Oui, nous sommes à Paris, puisqu'il s'agit d'un "Rêve parisien» et non du «rêve d'un Parisien " qu'on pourrait envisager assoupi au pied de quelque monument séculaire de Grèce, de Rome ou de l'Empire ottoman. La clé du poème intervient à la dernière strophe et transporte l'entière fantasmagorie en Île-de-France:

(«L'homme et la mer»: 19). Mais c'est dans Le Poème du hachisch (1860) que Baudelaire affirme avec le plus de conviction le caractère liquide de la pensée. Évoquant la fatigue des lendemains de consommation, il écrit: "Une grande langueur [...] s'empare de votre esprit et se répand à travers vos facultés, comme un brouillard dans un paysage. [...] C'est la punition de la prodigalité impie avec laquelle vous avez dépensé le fluide nerveux» (Baudelaire, Les Paradis artificiels: 426).

24. La métaphore s'atteste nombre de fois dans Les Fleurs du Mal, dont dans "Le mort joyeux", où l'explicitation de l'analogie engage jusqu’à l'aspect physique des invertébrés, rejoignant la nature graphique de lignes d'encre étendues sur le papier: "Ô vers! noirs compagnons sans oreille et sans yeux» (Baudelaire, "Le mort joyeux»: 70).

25. L'exemple d' «À une madone» est éloquent: le poète y joue à la fois de l'homophonie du verre, de ses propriétés d'usage commun (contenance du récipient, transparence de la vitre), de ses potentialités optiques (il peut être irisé, coloré, soufflé...) et de son statut de matériau traditionnel des arts somptuaires (verrerie, cristallerie, miroiterie, vitrail, bijouterie, verroterie), afin de composer un diadème en l'honneur de celle vers qui va sa pensée, et qui sait la recevoir: «Avec mes Vers polis, treillis d'un pur métal/Savamment constellé de rimes de cristal,/Je ferai pour ta tête une énorme Couronne» (Baudelaire, "À une madone»: 58).

26. Jean Starobinski (1989: 76-77) a étudié l' «élan» que produit cette préposition directionnelle dans «Le cygne». 
La pendule aux accents funèbres

Sonnait brutalement midi,

Et le ciel versait des ténèbres

Sur le triste monde engourdi. ("Rêve parisien»: 103).

S'il est midi sonnant, ces ténèbres versées par le ciel ne peuvent être celles du soir ou de la nuit. Elles sont - forcément - celles d'une pluie noire inondant Paris de ses nuées.

Voilà où prend tout son sens l'insistance du poète, qui appuie sur le caractère "dompté» de ce splendide fleuve rêvé. On sait que les biographes de Baudelaire ont souvent relevé ce trait de caractère chez lui: son dédain des formes naturelles - dandysme provocateur qui est aussi ras-le-bol des exaltations rousseauistes du romantisme ${ }^{27}$. S'arrêter à de telles considérations revient à manquer le poème. Car ce qui compte dans le «Rêve parisien", c'est le changement de rapport de forces: la mainmise qu'exerçait le poète, dans le songe, sur l'ensemble de ces eaux fantastiques l'érigeait en démiurge tout puissant et, par contraste avec la dure réalité du réveil, cette maitrise perdue exacerbe l'impuissance qu'il éprouve face à la nature qui ce jour-là jette sur les Parisiens un flot torrentiel d'eaux ternes, voire sales, bien différentes des précieuses "pierreries» rêvées.

Blessure d'orgueil plus grave encore, le poète détrompé est à même de constater que c'est la pluie dehors qui a si divinement inspiré sa psyché assoupie, de sorte qu'il se trouve dépossédé, même, de ce songe dont il a cru pouvoir se flatter en "peintre fier de [s]on génie» ("Rêve parisien»: 101); le rêve n’a jamais existé, pas plus que la mainmise. Rêver lui a permis de transmuer la vapeur d'eau informe en coulées liquides façonnées à sa guise, certes. C'était joli, mais tout est parti en fumée, conséquence peut-être d'une surchauffe cérébrale ou de ces "yeux pleins de flamme» qu'au réveil il promène avec horreur sur « $[s]$ on taudis» (103).

Par ce jeu entre les fluides parisiens et la subjectivité du poète se trouve rétablie la continuité organique ou corporelle dont Joseph Acquisto (2008-2009: 30-32) fait une caractéristique des Fleurs du Mal "pré-urbaines" (celles du recueil de 1857): moins distancié de son objet et moins aliéné par lui qu'on pense, le poète baudelairien se laisse inspirer et même toucher par la réalité objective. L'antagonisme qui s'affirme alors envers elle est finalement heureux, car sublime: de lui émerge la création poétique. Au contraire de ce que laisse supposer une lecture superficielle de l'univers liquide chez Baudelaire, l'eau n'a pas disparu dans le Paris des Tableaux parisiens. Dans "Le cygne», elle a été captée par l'œil du poète, siphonnée ainsi, et il l'a emportée avec lui, l'a ruminée et l'a ensuite coulée dans ses vers, pour nous la transmettre. Dans «Rêve parisien ", elle est entrée chez lui, l'a subrepticement bercé d'illusions puis l'a surpris; lui, aussi glacé par ce contact froid qu'il fut foudroyé de croiser la «Passante», s'en est servi comme matériau premier pour rêver de poésie. Il devient difficile, alors, d'affirmer que chez Baudelaire les constructions solides et rigides de l'haussmannisation s'opposent au fluide poétique (Acquisto 2008-2009: 38), à moins d'ajouter du même souffle qu'elles en sont la canalisation nécessaire, par le fait même qu'elles sont l'incarnation matérielle du vers.

À bien y regarder, il devient enfin possible de répondre à notre interrogation première: où est la Seine dans les Tableaux parisiens? Dire de la Seine qu'elle est partout est aussi facile et presque

27. Tel vieil ami qui semble garder en tête le «Rêve parisien" racontera, quelque vingt ans après la mort du poète, avoir entendu l'auteur des Fleurs du Mal évoquer l'horreur que lui inspiraient les rivières sauvages: «L'eau en liberté m'est insupportable; je la veux prisonnière, au carcan, dans les murs géométriques d'un quai. Ma promenade préférée est la berge du canal de l'Ourcq" (Alexandre Schanne rapportant en 1886 les paroles de Baudelaire, cité par Citron 1961 : t. II, 360). 
aussi inexact que d'affirmer qu'elle n'est nulle part. Elle est dans l'œil du poète, dans sa tête, dans son lit, évanouie. Demeure l'extase d'avoir pu créer "ce terrible paysage,/Tel que jamais mortel n'en vit» (Baudelaire, «Rêve parisien»: 101) : image transposée, grandie, embellie, sublimée du paysage parisien sempiternellement envahi d'une humidité ubiquitaire. Paysage que le poète connaît trop bien pour ne pas le rêver autre... et s'éveiller ensuite au cauchemar du fade quotidien.

\section{"Les sept vieillards»}

Il n'est pas indifférent que le poème qui précède immédiatement le «Rêve parisien » dans les Tableaux parisiens s'intitule "Brumes et pluies». Celui-ci loue les "fins d'automne, hivers, printemps trempés» pour leur aptitude à envelopper le cour et le cerveau "D'un linceul vaporeux» (Baudelaire, "Brumes et pluies»: 100). Mais c'est le poème "Les sept vieillards» qu'il faut parcourir si l'on cherche un alexandrin capable de résumer parfaitement la prolifération des brumes à travers l'étendue urbaine que présente cette deuxième section des Fleurs du Mal: «Un brouillard sale et jaune inondait tout l'espace " (87). Inlassablement dans ces dix-huit "tableaux» est soulignée de la sorte l'atmosphère brumeuse et capricieuse de Paris. Et ce que permet d'illustrer ce poème particulier, écrit tout entier à Honfleur (cela n'est pas indifférent, on le verra), est la façon dont le poète sillonnant la ville s'y prend pour transformer par son seul regard les vapeurs diffuses, les flous indécis, en cours d'eau. Baudelaire y mentionne d'entrée de jeu la "cité pleine de rêves", sorte de prolepse qui annonce le "Rêve parisien" à venir, puis, accordant la rime avec "sève", il précise que "Les mystères partout coulent» de la sorte, menés «Dans les canaux étroits du colosse puissant» ("Les sept vieillards»: 87). Vite on s'aperçoit que dans l'esprit du poète les canalisations en question, celles qui guident les eaux de Paris (usées et fraîches), ne se limitent point à celles qu'un expert hydrographe saurait nommer par cœur: le réseau d'égouts en réfection sous le Second Empire, le Canal Saint Denis (achevé en 1821), le Canal Saint Martin et le Canal de l'Ourcq (tous deux inaugurés en 1825). Sous la plume de celui qui aime puiser son inspiration "Dans les plis sinueux des vieilles capitales" (Baudelaire, "Les petites vieilles»: 89), chaque rue, chaque ruelle, la plus petite ride sur la physionomie de Paris, ce titan fait de pierre, de marbre, de métal et d'eau, est susceptible en effet d'accueillir un flot et de le faire courir le long de ses parois. Car pour le poète le «ciel pluvieux» («Les sept vieillards»: 87) perturbe la vision, brouille la netteté des contours. Ainsi, "Les maisons, dont la brume allongeait la hauteur,/Simulaient», affirme-t-il, "les deux quais d'une rivière accrue» (87). Et c'est bien là, au fond de ce lit de rivière simulée, équivoque autant que le Simoïs du "Cygne» était menteur, que passe une série ahurissante de vieillards tous pareils comme deux gouttes d'eau.

Spectacle hypnotique, que cette rivière de vieillards! torrent inépuisable d'individus «March[ant] du même pas vers un but inconnu» (88). "Nul trait» ne les "distingu[e]» (88) et pourtant ils sont distincts, car successifs. On connaît le proverbe attribué à Héraclite qui veut qu'on ne se baigne jamais deux fois dans le même fleuve, suggérant qu'à tout point d'une berge l'eau se renouvelle sans cesse et que le lit, le niveau, le débit d'une rivière évoluent de jour en jour. De fait, "Ce sinistre vieillard qui s['est] multiplié] » en passant "sept fois» (88) devant les yeux du poète rappelle l'avancée tenace d'un fleuve, voie de circulation qui descend inlassablement à la mer avec une obstination lui ayant valu d'être appelée, autant par les Français de l'Ancien Régime qu'au Canada par les Amérindiens riverains du St-Laurent, «le chemin qui marche» (Petit 2001: 8).

Sept vieillards ont été comptés "de minute en minute» (88) comme on compte les nœuds d'une corde pour mesurer sa vitesse sur l'eau. Peut-être y en avait-il davantage? une infinité? Qui sait! puisque 
dans son effarement le poète a "tourn[é] le dos au cortège infernal» (88). Tout à la tourmente ayant envahi son esprit, il s'explique, tant bien que mal - encore déboussolé - au dernier quatrain du poème:

Vainement ma raison voulait prendre la barre;

La tempête en jouant déroutait ses efforts,

Et mon âme dansait, dansait, vieille gabarre

Sans mâts, sur une mer monstrueuse et sans bords! («Les sept vieillards»: 88).

Visiblement, le poète éberlué a eu beau détourner son regard, il s'est trouvé emporté par le courant, passé le Havre, passé l'embouchure du fleuve, devant Honfleur, charrié jusqu'au milieu de l'océan.

En d'autres termes, le poète baudelairien, ici encore, s'est servi de la Seine, fleuve familier, référent réel et apparemment indifférent (mais seulement en apparence!), comme d'un tremplin formidable, tremplin sans pareil, pour se plonger dans l'ailleurs exotique, mouvant et infini qu'est l'univers immatériel de la pensée. Ici, c'est une pensée dévoyée, défaillante. Si le poète des "Sept vieillards» s'était entêté un peu plus, il en aurait peut-être vu d'autres passer, des dizaines d'autres. Mais le huitième est mentionné, dans le texte publié, comme éventualité non actualisée; l'étude des manuscrits et brouillons révèle que l'auteur longtemps songea aussi «Au neuvième! au possible, au probable, au fatal!» (Baudelaire cité par Pichois 1975b: 1013). Ce neuvième fut éliminé: il est inutile et même contreproductif de multiplier les occurrences de ce qu'on préfère garder indéterminé. Baudelaire a eu soin d'assurer que la version définitive du texte soit, sur ce point précis, le moins définitive possible.

De fait, sur le plan symbolique, il importe que le septième eût pu également être le tout dernier. S'étant détourné du spectacle, le poète n'aura jamais l'heure juste, le doute lui restera. De quoi perdre la raison, vraisemblablement - mais ce n'est qu'à ce prix qu'on met fin à ce genre de spectacle, dont le pouvoir d'attraction tient justement au fait que contempler l'écoulement d'un fleuve implique de s'oublier devant la succession de «Sosie[s] inexorable[s], ironique[s]» («Les sept vieillards»: 88). Le risque qu'ils deviennent «fatal[s]» (88) - au sens de mortels pour celui qui fasciné les regarde - concerne la possibilité, toujours réelle, qu'on ne sache s'y arracher et qu'à l'instar de Narcisse on y reste, entièrement absorbé par les flots.

Le public put découvrir les Tableaux parisiens de Baudelaire pour la première fois lorsque, en février 1861, fut mise en vente la nouvelle édition des Fleurs $d u$ Mal, qui arborait la mention suivante: "Seconde édition augmentée» (Pichois 1975b: 810). L'auteur envoya un exemplaire à Alfred de Vigny en décembre de la même année, accompagné d'une lettre où il affirmait crânement: «Tous les anciens poèmes sont remaniés» (Baudelaire, Correspondance: t. II, 195). Cette déclaration abusive (la plupart restaient intacts) n'est admissible que si l'on accepte l'axiome selon lequel ajouter un élément à un tout, c'est changer l'ensemble entier. La suite de la lettre tend à confirmer une telle perspective: «Le seul éloge que je sollicite pour ce livre est qu'on reconnaisse qu'il a un commencement et une fin. Tous les poèmes nouveaux ont été faits pour être adaptés au cadre singulier que j'avais choisi» (Baudelaire, Correspondance: t. II, 196). Chacun des poèmes apportés par cette refonte est donc à considérer comme faisant partie intégrante du recueil; c'est ce qu'on peut déduire de la seconde phrase. Et chacun, ainsi que l'atteste la première, mérite d'être aussi envisagé comme s'inscrivant à l'intérieur d'une séquence progressive. Allant plus loin, puisque chacun a été «fait» avec le recueil primitif comme arrière-plan, les nouveaux poèmes se trouvent à instituer, ne serait-ce que de biais, une forme 
de réponse, de commentaire ou de glose par rapport aux pièces antérieures. Elles en sont amplifiées, augmentées.

Les quatre Tableaux parisiens sur lesquels nous nous sommes arrêtés plus longtemps ont en commun de fonctionner eux-mêmes de la sorte, par des renvois internes. Deux d'entre eux sont explicitement des diptyques, "Le cygne» et "Rêve parisien": leur second volet se replie sur le premier pour multiplier les reflets spéculaires et ainsi forcer le lecteur à réévaluer les valeurs initialement exposées. Le redoublement de la lecture obéit à celui du texte. Quant au premier des Tableaux parisiens, "Paysage», Pierre Laforgue a brillamment montré qu'il met le lecteur "en présence de deux paysages» s'appelant l'un l'autre, articulés "autour du couple "je verrai"“"je rêverai”" (Laforgue 1995: 82 ${ }^{28}$ ). Il ne serait pas difficile d'établir que l'effet se réitère dans "Les sept vieillards" à partir de la strophe où le poète «tourn[e] le dos au cortège infernal» (88): après tout, Honfleur est «l'autre de Paris», comme le dit si bien Jérôme Thélot (1995: 137).

Au-delà des divers effets d'écho sur lesquels la critique baudelairienne aime s'appesantir, il faut donc observer que, quelle que soit l'échelle (poème, section, recueil), chaque atome des Fleurs $d u$ Mal est susceptible de se doubler en appelant son semblable au fil de la lecture et des réminiscences. L'analyse de la présence de la Seine dans les Tableaux parisiens révèle que cela produit, au sein du tout, un faisceau de réverbérations communiquant en surface ou en profondeur avec la masse des autres, par ondes tangibles ou secrètes, connexes ou lointaines, abruptes ou fondues, par reflets directs ou obliques, nets ou diffus, ensoleillés ou macabres. Mille éclats fugaces scintillent alors, tels que ceux émis par les vaguelettes dansantes qui donnent à un fleuve son relief tout en témoignant de sa mouvante coulée.

Ainsi, chercher la Seine, l'entrevoir, la débusquer çà ou là, au détour de quelque détail historique, symbolique ou langagier, cela aura été pour nous, par un étonnant jeu réflexif qui engage la matérialité même du fleuve, éclairer la poétique baudelairienne des réalités urbaines. Pour bien la voir et la lire il a fallu, chose fréquente chez Baudelaire, étudier ses mentions obliques. Référent plus mythographique que réel, mis au service d'analogies de surface ou abyssales, et singulièrement peu investi dans la représentation picturale (dont les séductions poétiques sont pourtant attestées partout ailleurs), la Seine nous est apparue, entre les lignes, tout à fait urbaine et humaine, ni naturelle ni pittoresque, mais volontiers allégorique. Nimbée de la majesté des symboles qui charrient leur lot de matériaux poétiques immédiatement disponibles et constamment renouvelés, étant mus par une déferlante de signes enchaînés les uns aux autres, elle s'est avérée puissante et discrète, souvent presque secrète, toujours malléable sous l'œil du poète et docile aux visions qui, comme j'ai pu le montrer, confinent à l'invention. C'est pourquoi dire à propos de la poésie de Baudelaire qu'elle est perception plutôt que mimésis (Acquisto 2008: 290) revient à faire l'impasse sur la psyché fertile que le poète ne cesse de mettre en scène - notamment par la Seine, qui ne se borne pas à éveiller une mémoire. Elle la féconde.

\section{Références bibliographiques}

Acquisto, J. 2008. «Reading echoes in Baudelaire: Between philosophic and Genetic Approaches». Romance Studies 26 (4): 286-296.

Acquisto, J. 2008-2009. «Digesting Les Fleurs du Mal: Imaginative Spaces and Liquid Modernity in Baudelaire». Nineteenth-Century French Studies 37 (1-2) (hiver-automne) : 30-41.

28. C'est par un même "effet de scissiparité» que la «division réel/imaginaire» est inscrite dans le premier poème de la section puis «redoublée» dans l’avant-dernier, «Rêve parisien» (Laforgue 1995: 83). 
Apollinaire, G. 2000. «Le Pont Mirabeau». Dans Alcools, suivi de Le Bestiaire et de Vitam impendere amori. Paris: Gallimard: 15-16. [1913].

Balzac, H. 1980. Louis Lambert. Dans Louis Lambert, Les Proscrits, Jésus-Christ en Flandre, préface de Raymond Abellio, édition établie et annotée par Samuel S. de Sacy. Paris: Gallimard : 23-176. [1836].

Baudelaire, C. 1973. Correspondance, texte établi, présenté et annoté par Claude Pichois avec la collaboration de Jean Ziegler. Paris: Gallimard (Bibliothèque de la Pléiade) : 2 vol.

Baudelaire, C. 1975. La Fanfarlo. Dans Euvres complètes, texte établi, présenté et annoté par Claude Pichois. Paris: Gallimard (Bibliothèque de la Pléiade) : t. I, 553-580. [1847].

Baudelaire, C. 1975. Les Paradis artificiels. Dans Euvres complètes, texte établi, présenté et annoté par Claude Pichois. Paris: Gallimard (Bibliothèque de la Pléiade): t. I, 399-517. [1860].

Baudelaire, C. 1975. Les Fleurs du Mal, $2^{\mathrm{e}}$ édition. Dans Euvres complètes, texte établi, présenté et annoté par Claude Pichois. Paris: Gallimard (Bibliothèque de la Pléiade) : t. I, 1-178. [1861].

Baudelaire, C. 1975. "À Sainte-Beuve». Dans CEuvres complètes, texte établi, présenté et annoté par Claude Pichois. Paris: Gallimard (Bibliothèque de la Pléiade) : t. I, 206-208. [1886].

Baudelaire, C. 1976. Théophile Gautier. Dans Euvres complètes, texte établi, présenté et annoté par Claude Pichois. Paris: Gallimard (Bibliothèque de la Pléiade) : t. II, 103-128. [1859].

Baudelaire, C. 1976. Le Peintre de la vie moderne. Dans Euvres complètes, texte établi, présenté et annoté par Claude Pichois. Paris: Gallimard (Bibliothèque de la Pléiade) : t. II, 683-724. [1863].

Beaudouin, F. 1989. Paris/Seine, préface de Jean-Pierre Babelon. Paris: Nathan.

Carpenter, S. 2006. «Entre rue et boulevard: les chemins de l'allégorie chez Baudelaire». Romantisme 134: 55-65.

Charest, N. 2008. Vaisseau, le grand Poème: Coleridge, Poe, Baudelaire, Rimbaud, Mallarmé, Nelligan, Valéry. Québec: Nota Bene.

Citron, P. 1961. La Poésie de Paris dans la littérature française de Rousseau à Baudelaire. Paris: Minuit: 2 vol.

Coëtlogon, A. 1874. Les Armoiries de la ville de Paris: sceaux, emblèmes, couleurs, devises, livrées et cérémonies publiques, ouvrage commencé par feu le Cte A. de Coëtlogon; refondu et complété par L.-M. Tisserand et le Service historique de la ville de Paris. Paris: Imprimerie nationale: t. I.

Declerck, M. 2007. Les Armoiries de Paris (Histoire-Documents). Paris: L'Harmattan.

Delille, J. 1821. «Remarques sur le livre troisième». Dans Virgile, L’Énéide, traduite en vers français par J. Delille, $3^{\mathrm{e}}$ édition, revue et corrigée, avec les variantes, des notes et des remarques sur les principales beautés du texte. Paris: Michaud: t. I, 350-398.

Fongaro, A. 1988. Quelques images dans Les Fleurs du Mal. Toulouse: Presses universitaires du Mirail.

Gaillard, M. 1982. Quais et Ponts de Paris, photographies de Jean-Marc Durou et Joël Jaffre. Paris: Moniteur.

Gaillard, M. 2002. Paris sous le Second Empire: au temps de Charles Baudelaire. Etrepilly (France): Presses du Village.

Gasarian, G. 1995. «Dyptique parisien». L’Année Baudelaire 1: 57-69.

Gautier, T. 2004. Euvres poétiques complètes, édition établie, présentée et annotée par Michel Brix. Paris: Bartillat.

Haussmann, G. E. 1893. Mémoires du baron Haussmann. III: Grands Travaux de Paris. Paris: Havard.

Hugo, V. 1964. "À Virgile». Dans Euvres poétiques, préface par Gaëtan Picon, édition établie et annotée par Pierre Albouy. Paris: Gallimard (Bibliothèque de la Pléiade): t. I, 959-961. [1837].

Labarthe. P. 1995. «Paris comme décor allégorique». L'Année Baudelaire 1: 41-55.

Laforgue, J. 1979. Les Complaintes suivies des Premiers poèmes, édition présentée, établie et annotée par Pascal Pia. Paris: Gallimard. [1885].

Laforgue, P. 1995. «Note sur les Tableaux parisiens». L'Année Baudelaire 1: 81-87.

Larousse P. 1875. «Tableau». Dans Grand Dictionnaire universel du XIX siècle. Paris: Administration du grand Dictionnaire universel: t. XIV, 1374-1376. 
Le Siècle. 1837. «De la loi pour l'amélioration des rivières. - Rapport de M. le Marquis de Dalmatie». Le Siècle (Paris) (161) (13 juin 1837): 1.

Littré, É. 1874. «Tableau ». Dans Dictionnaire de la langue française. Paris: Hachette: t. IV, 2124.

Nelson Jr., L. 1961. "Baudelaire and Virgil: A Reading of "Le Cygne” ». Comparative Literature 13 (4) (Automne): 332-345.

Petit, J.-G. 2001. «Introduction: fleuves canadiens et construction identitaire». Études canadiennes 27 (50): $7-13$.

Pichois, C. 1973. «Notes et variantes». Dans Charles Baudelaire, Correspondance, texte établi, présenté et annoté par Claude Pichois avec la collaboration de Jean Ziegler. Paris: Gallimard (Bibliothèque de la Pléiade) : 2 vol.

Pichois, C. 1975a. «Chronologie». Dans Charles Baudelaire, Euvres complètes, texte établi, présenté et annoté par Claude Pichois. Paris: Gallimard (Bibliothèque de la Pléiade) : t. I, XXV-LVII.

Pichois, C. 1975b. «Notice, notes et variantes». Dans Charles Baudelaire, Euvres complètes, texte établi, présenté et annoté par Claude Pichois. Paris: Gallimard (Bibliothèque de la Pléiade) : t. I, 787-1224.

Pichois, C. et J.-P. Avice. 2004. Baudelaire Paris sans fin, préface d'Yves Bonnefoy. Paris: Paris Musées; Paris Bibliothèques.

Richard, J.-P. 1955. Poésie et profondeur. Paris: Seuil.

Rimbaud, A. 1999. "Le Bateau ivre». Dans Poésies, Une saison en enfer et Illuminations, préface de René Char, édition établie et annotée par Louis Forestier. Paris: Gallimard: 122-126. [1871].

Saminadayar-Perrin, C. 2001. «Baudelaire poète latin». Romantisme 113: 87-103.

Starobinski, J. 1989. La Mélancolie au miroir: trois lectures de Baudelaire. Paris: Juillard.

Stierle, K. 1980. "Baudelaire and the Tradition of the Tableau de Paris». New Literary History 11 (2) (hiver): 345-361.

Thélot, J. 1995. «Paris/Honfleur: ou l'impossibilité d'œuvrer». L’Année Baudelaire 1: 133-146.

Verlaine, P. 1972. "Nocturne parisien». Dans Poèmes saturniens. Dans Euvres poétiques complètes, texte établi et annoté par Yves-Gérard Le Dantec, édition révisée, complétée et présentée par Jacques Borel. Paris: Gallimard (Bibliothèque de la Pléiade) : 83-86. [1866].

Virgile. 1821. L'Énéide, traduite en vers français par J. Delille, $3^{\mathrm{e}}$ édition, revue et corrigée, avec les variantes, des notes et des remarques sur les principales beautés du texte. Paris: Michaud: 4 vol. [29-19 av. J.-C.].

Virgile. 1862. L'Énéide, expliqué par Édouard Sommer, traduit et annoté par Auguste Desportes. Paris: Hachette: 12 vol. [29-19 av. J.-C.].

Virgile. 1925-36. L'Énéide, texte établi par Henri Goelzer et traduit par André Bellessort. Poitiers: Société française d'imprimerie; Paris: Les Belles Lettres: 2 vol. [29-19 av. J.-C.]. 